\title{
Surface pollen distribution patterns in Beibu Gulf and corresponding sediment dynamics environment
}

\author{
TONG GuoBang ${ }^{1 *}$, CHEN Liang $^{2}$, LONG JiangPing ${ }^{3}$, LI TuanJie $^{2}$, XIAO XiaYun $^{4} \&$ \\ TONG SongMei ${ }^{1}$ \\ ${ }^{1}$ Institute of Hydrogeology and Environmental Geology, Chinese Academy of Geological Sciences, Shijiazhuang 050061, China; \\ ${ }^{2}$ South China Sea Marine Engineering Surveying Center, State Oceanic Administration, Guangzhou 510300, China; \\ ${ }^{3}$ Second Institute of Oceanography, State Oceanic Administration, Hangzhou 310012, China; \\ ${ }^{4}$ State Key Laboratory of Lake Science and Environments, Nanjing Institute of Geography and Limnology, Chinese Academy of Sciences, \\ Nanjing 210008, China
}

Received September 20, 2011; accepted November 23, 2011; published online December 30, 2011

\begin{abstract}
The Beibu Gulf is a semi-enclosed gulf in the northwest of the South China Sea. We palynologically analyzed 306 surface sediment samples from the eastern Beibu Gulf to improve bioclimatic interpretation of fossil pollen records there. Surface pollen assemblages could be classified into five pollen regions based on the distributions of total, arboreal, herbaceous and fern pollen concentrations. Four high-concentration and three low-concentration subregions could be distinguished within these regions. The distribution patterns of surface pollen assemblages were consistent with those of grain sizes of surface sediments. Sediments from regions with high pollen concentrations were very fine and fine silts $(>7.0 \Phi,<0.008 \mathrm{~mm})$, whereas those with low pollen concentrations were fine sand $(<3.5 \Phi,>0.088 \mathrm{~mm})$. Sedimentary heterogeneity of surface pollen assemblages was closely related to pollen source, transportation and sedimentation controlled by ocean currents, tides and waves, and oceanic bottom topography. Fern spores exhibited higher percentages along the east margins of the region, while arboreal types like Pinus increased in concentration towards the center. Herbaceous pollen appeared in high percentages around seacoasts near their source areas. Dacrydium and mangrove pollen were distributed near their source regions at low percentages. We discuss the sediment dynamic environments in the eastern Beibu Gulf based on surface pollen distributions. The estuary region is an important access to the sea basin and a depositional site for terrestrial pollen grains. Coastal regions can accumulate pollen due to the back-and-forth movements of tides there. Although ocean currents on a gulf scale tend to spread pollen grains, the interaction of multiple currents could lead to pollen accumulation and deposition. Low surface pollen concentrations in the northeast shallow-water regions of the eastern Beibu Gulf could be attributed to repeated washing and sediment floatation caused by severe wave activities during the summer. Strong tides in Qiongzhou Strait frequently wash the seabed and disadvantage pollen deposition, leading to low surface pollen concentrations there.
\end{abstract}

Beibu Gulf, surface sediment, pollen, high-concentration deposition subregion, sediment dynamic environment

Citation: Tong G B, Chen L, Long J P, et al. Surface pollen distribution patterns in Beibu Gulf and corresponding sediment dynamics environment. Chin Sci Bull, 2012, 57: 902-911, doi: 10.1007/s11434-011-4912-2

In recent years, palynological research on surface marine sediment has tended to focus on the distribution, transmission and sedimentation of pollens, and their relationships to terrestrial vegetation. In the 1950s, Muller [1] studied surface pollen in the coastal and nearshore zones of the Ori-

*Corresponding author (email: guobangtong@263.net) noco Delta in the Caribbean Sea and analyzed the influences of source areas and atmospheric and water transmission on pollen distribution. More recently, Melia [2], Hooghiemstra and Agwu [3], Hooghiemstra et al. [4], Dupont et al. [5], and Campo and Bengo [6] studied the relationship between surface pollen distribution in the Guinea Gulf and wind and water transport, and explored the distribution patterns of 
major pollen types in surface sediments from these sea areas. Beaudouin et al. [7] analyzed modern pollen assemblages in terrigenous sediments in the Lions Gulf of the western Mediterranean. In their opinions, surface pollen assemblages with low concentrations in the Gulf were mainly brought in by winds and reconstructed by resuspension and redeposition on the continental shelf. Crouch et al. [8] investigated surface pollen distributions in the eastern sea of New Zealand with 38 surface sediment samples and found out that $10 \%$ of the pollens found in the upwelling area of Chatham were angiosperm types carried from source areas in the north by subtropical surface currents. In China, Wang et al. $[9,10]$ and Yang and Chen [11] performed surface pollen investigations in the Yellow Sea, East China Sea, and Hangzhou Gulf and demonstrated that the pollen sources were terrestrial vegetation on the continental margins of eastern China. According to Sun and Li's study [12] in the South China Sea, winter monsoons and ocean currents were the main agents for pollen transport, and thus the large amounts of pine pollen should be carefully considered when reconstructing paleovegetation and paleoenvironment there. Zhang et al.'s $[13,14]$ investigation on surface pollen in the northeast South China Sea and sea area around Hainan Island highlighted similarities in surface pollen assemblages and vegetation on continental margins and certain differences attributed to varying pollen production, ocean currents, sediment types and submarine topography. These studies of pollen assemblages of marine surface sediments have provided important references for the reconstruction of paleovegetation and paleoenvironment based on fossil pollen records.

The Beibu Gulf is a semi-enclosed gulf in the northwest of the South China Sea. Increasing knowledge of the natural environments and resources in this sea area will provide an important basis for environmental protection and resource development as well as environmental interpretation for Quaternary science and petroleum exploration. In this study, we conducted an investigation of pollen distribution using 306 surface sediments from the Beibu Gulf and analyzed the corresponding sedimentary dynamics. Our work would provide basic data for the bioclimatic interpretation of fossil pollen records in the Beibu Gulf and for comparison of marine and terrestrial environmental changes.

\section{Study area}

We have sampled surface sediments in the eastern Beibu Gulf between $20.0^{\circ}-21.6^{\circ} \mathrm{N}$ and $108.1^{\circ}-110.4^{\circ} \mathrm{E}$, from Leizhou Peninsula in the east to the central part of the Beibu Gulf in the west, and from the Nanliu River estuary in the north to the northern sea of Hainan Island in the south. The inflow rivers included the Nanliu, Dafeng, Qinjiang, Maoling, Fangcheng and Beilun rivers from the coast of Guangxi in the north, the Red River from Vietnam in the west, the Nandu River from Hainan Island in the south, and the Leizhou Qingnian Canal from Leizhou Peninsula. The water depth in this area was less than $60 \mathrm{~m}$. The seafloor was relatively flat although it was higher in the northeast and lower in the southwest. Northeast monsoons prevailed over this area in the winter, and southwest monsoons prevailed in the summer. Vegetation types around the study area were composed of tropical-subtropical grasslands in southern Guangxi on the north coast and Leizhou Peninsula on the east [15]; tropical rainforest and monsoon forest in Hainan Island in the south; tropical rainforest, monsoon forest and cropland in Vietnam in the west; and subtropical broad-leaved evergreen and subtropical coniferous forests in the drainage of Yuan River in China [16]. Figure 1 summarizes the locations of the study area, surrounding rivers, and sampling sites.

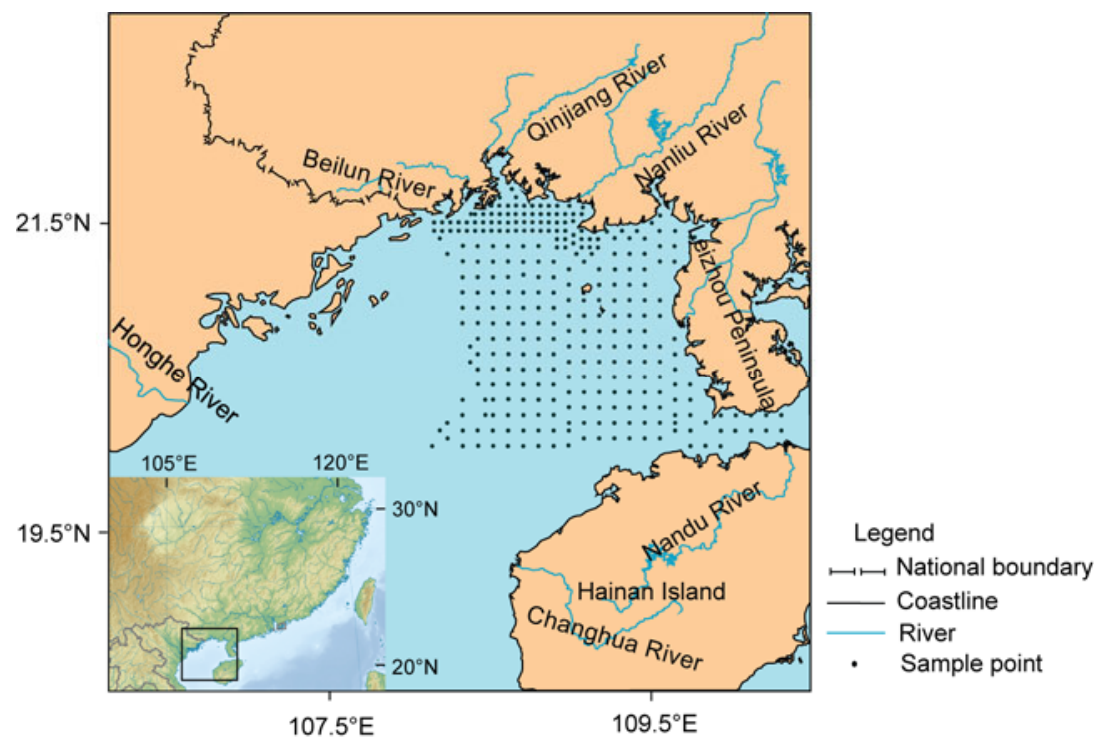

Figure 1 Study area and sampling sites in the Beibu Gulf. 
Ocean currents in the Beibu Gulf consist mainly of cyclonic circulation currents on a gulf scale, coastal currents, upwelling in South China Sea, and an eastern extension of the cold water mass from the Red River. The cyclonic current in the Beibu Gulf generally circulates counterclockwise in the winter, and thus wind stress was considered the main driving force. However, whether it rotated clockwise or counterclockwise in the summer was debated, opening to question whether summer circulation was a wind drift or a density current. Based on a simulation of wind drift and density currents in the Beibu Gulf and a comparison of the distributions of cold water mass and salinity between spring and summer, currents in the Gulf were shown to circulate counterclockwise year-round [17]; thus, the dominant driving force for summer residual currents along the coast of Guangxi should be a density gradient. The coastal current flows northward along the west coast of Hainan Island and turns westward along the coast of Guangxi after passing Leizhou Peninsula. A cold water mass moves from south to north in the western sea area of Hainan Island, bringing cold saline water up to the surface [18]. In addition, fresh water from the Red river and adjacent rivers brings low-salinity water to the middle-eastern Gulf through the counterclockwise circulation in the north [19]. There are also high-salinity ocean currents moving northwards from Qiongzhou Strait in the east [20]. The interaction among these ocean currents strengthens the cyclonic circulation in this area, and results in the transmission and deposition of pollen grains within the Beibu Gulf.

\section{Materials and methods}

From March to June of 2007, an ocean investigation in the Beibu Gulf was performed by the South China Sea Marine Engineering Surveying Center of the State Oceanic Administration (SOA) and the Second Institute of Oceanography of the SOA. More than 300 surface sediment samples less than $10 \mathrm{~cm}$ in depth were collected with a grab sampler during two voyages in the eastern sea area of the Beibu Gulf (Figure 1). In total, 306 surface sediment samples were palynologically analyzed [21]. After treating with hydrofluoric acid, samples were sieved with screen (aperture of $5 \mu \mathrm{m}$ ) in an ultrasonic tank, and then the residues were sealed with glycerol for pollen counting. If there were many impurities in the sample, a heavy liquid of zinc iodide with a specific gravity of 2.1 was used for floatation. Dyed Lycopodium spores were added to each weighted sample as indicators for calculation of pollen concentrations. We counted more than 500 grains for each sample and calculated pollen concentration as grains per gram of sediment. The percentages of terrestrial pollen types were calculated based on the total amounts of terrestrial types, while those of aquatic types (including hygrophilous ones) and fern spores were based on the total amounts of all types.

\section{Results}

In total, 200962 pollen grains belonging to 164 types were identified from 306 sediment samples. The average number of counted pollen grains in each sample was 657, and the mean concentration was 2653.2 grains/g. Arboreal pollen types accounted for $32.7 \%$, terrestrial herbaceous types for $8.9 \%$, aquatic herbaceous types for $0.2 \%$, and fern spores for $58.4 \%$. The arboreal pollen types mainly included Pinus, Castanopsis/Lithocarpus, Cyclobalanopsis, Euphorbiaceae, and other types with low percentages, such as Podocarpus, Dacrydium, Altigia, Hamamelidaceae, Anacardiaceae, Myrtaceae, Sapindaceae, and Myrsinaceae. Herbaceous pollen types mainly included Gramineae, Chenopodiaceae, Artemisia, and Cyperaceae as a hygrophilous type. Fern spores mainly included Dicranopteris/Microlepria, Polypodiaceae, Pteris, Cibotium and Lygodium.

Total pollen concentrations were very high $(>4500$ grains/g) in the northern area and gradually decreased towards the south (Figure 2(a)). The lowest pollen concentrations appeared in the northeastern and southeastern areas. Arboreal pollens occurred at high concentrations in the western area and at low concentrations in the east (Figure 2(b)), while that of fern types showed the opposite trend (Figure 2(d)). The concentrations of herbaceous types decreased from north to south (Figure 2(c)).

Five pollen regions, marked by I, II, III, IV, and V in Figure 3(a), could be distinguished. Pollen region I was characterized by high concentrations of total pollen $(>4500$ grains/g) and the highest concentrations of many types, especially herbaceous ones like Gramineae (Figure 2(c),(i)). The total pollen concentration in region II was about 2000 grains/g and was dominated by arboreal types, such as $P i$ nus, Cyclobalanopsis/Castanopsis/Lithocarpus and Dacrydium (Figure 2(b),(e)-(g)). In region III, total pollen concentrations were generally larger than 2000 grains/g with diagnostic high concentrations of fern spores (mainly Dicranopteris/Microlepria, Figure 2(d),(j)). In region IV, total pollen concentrations were between 500-2000 grains/g. Most pollen types had low concentrations there, but mangrove types occurred at relatively high concentrations (Figure 2(h)). Pollen region $V$ was characterized by low total pollen concentrations ( $<500$ grains/g) and various pollen types.

Distributions of pollen concentration were not homogeneous within each region. Four high-concentration subregions (marked by A, B, C and D in Figure 3(b)) were defined as deposition regions with the highest concentrations of major pollen types, and three low-concentration subregions as regions with the lowest concentrations (E, F and G in Figure 3(b)). These deposition subregions were characterized as follows.

High-concentration subregion A was oriented east-towest in the north sea area near estuaries of the Qinjiang, Fangcheng, and Nanliu rivers. Pollen concentrations there were generally greater than 4000 grains/g (>7000 grains/g in 

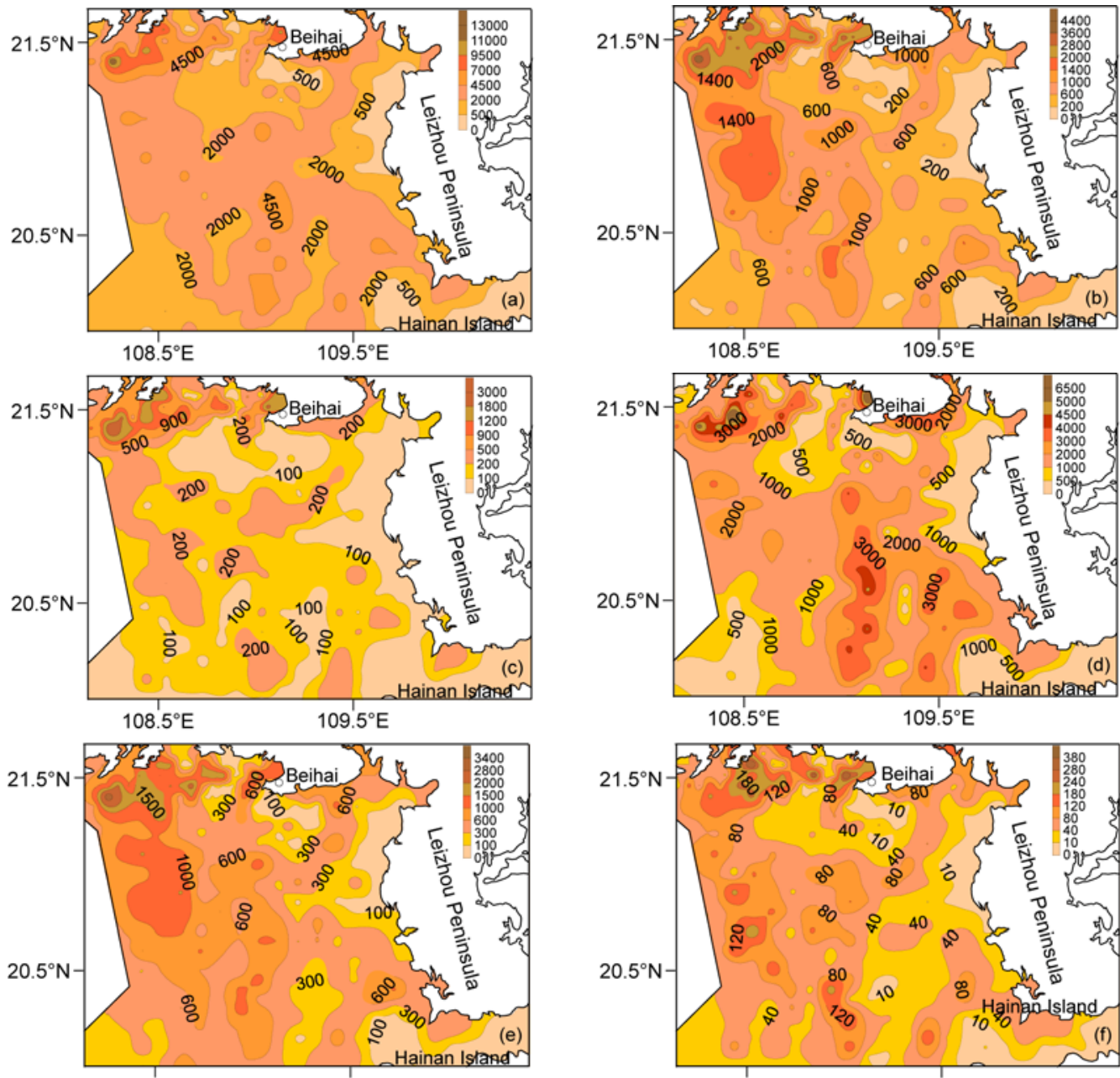

$108.5^{\circ} \mathrm{E} \quad 109.5^{\circ} \mathrm{E}$
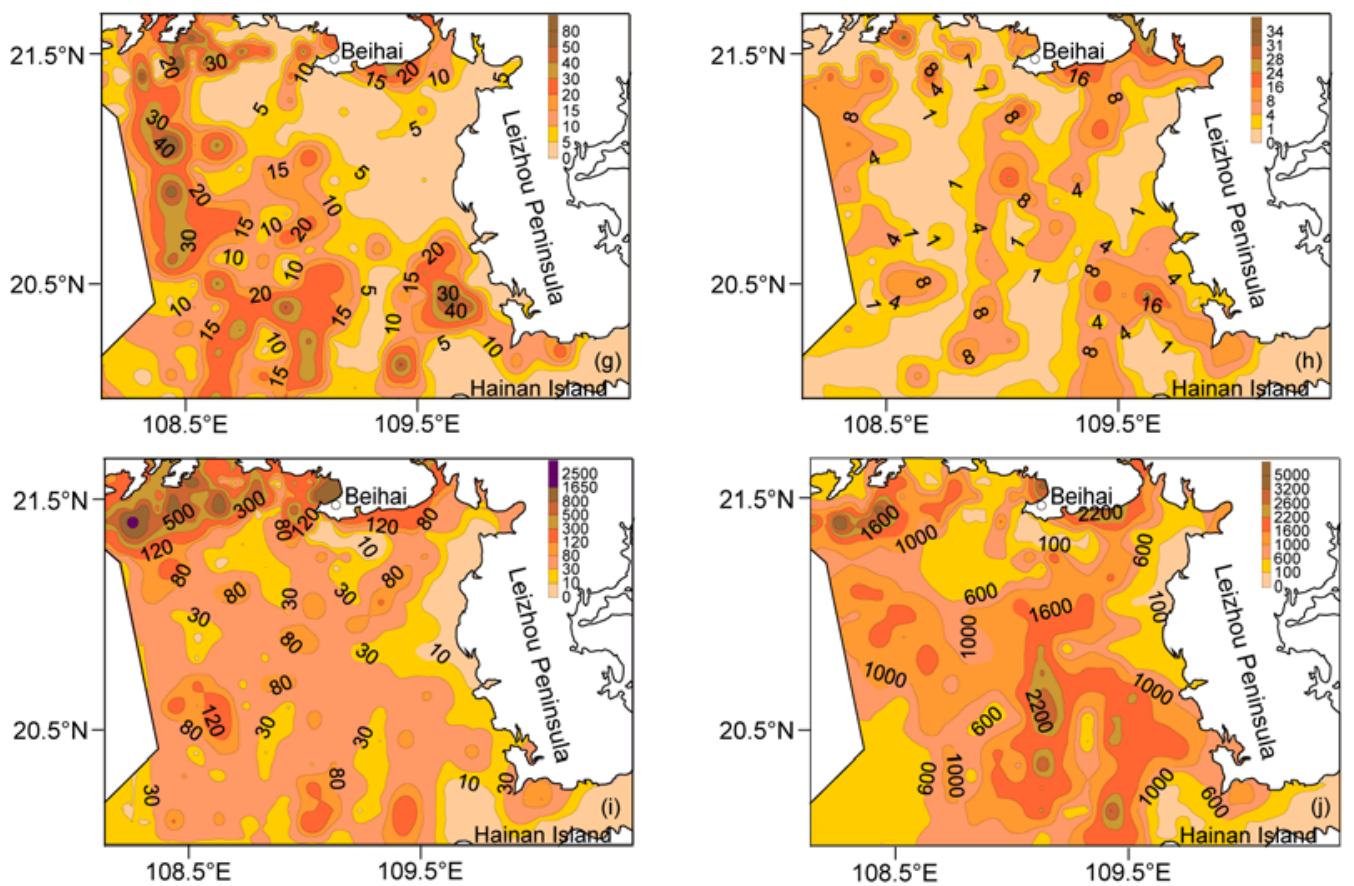

Figure 2 Concentration distributions of major pollen types (grains/g) in the eastern Beibu Gulf. (a) Total pollen concentration; (b) arboreal types; (c) herbaceous types; (d) fern spores; (e) Pinus; (f) Cyclobalanopsis/Castanopsis/Lithocarpus; (g) Dacrydium; (h) mangrove types; (i) Gramineae; (j) Dicranopteris/Microlepria. 

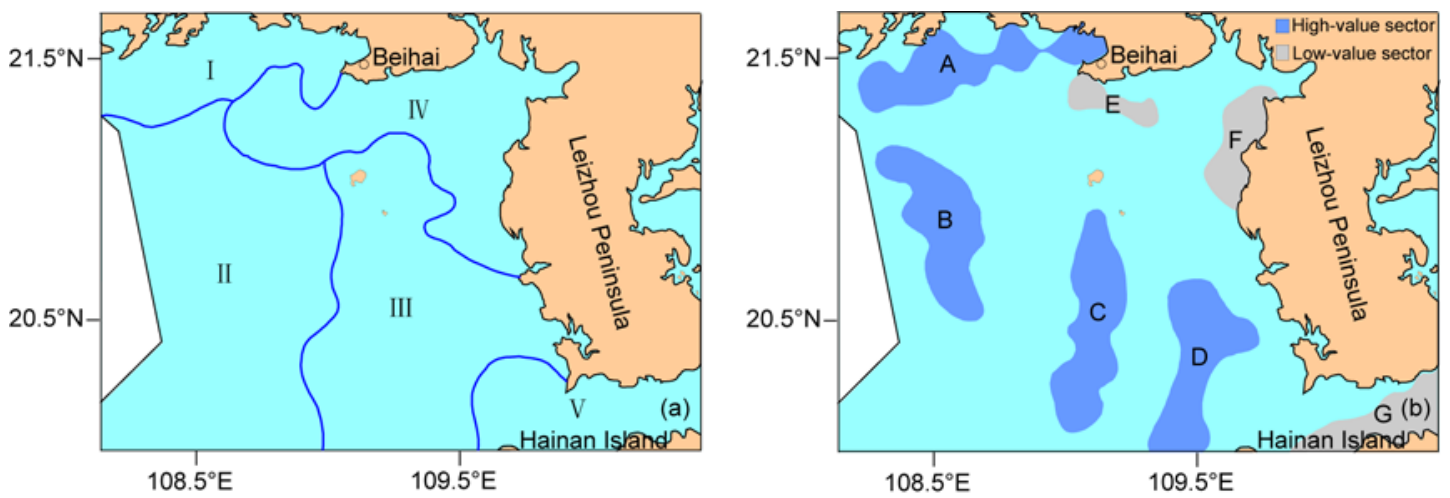

Figure 3 Pollen regions I, II, III, IV and V (a) and pollen deposition subregions (b) in the eastern Beibu Gulf. Subregions A, B, C and D were high-concentration deposition subregions, while $\mathrm{E}, \mathrm{F}$, and $\mathrm{G}$ were low-concentration subregions.

some samples) with predominant arboreal types, herbaceous types and fern spores. Subregion A included an east-west extension with a varying width. Pollen concentrations decreased sharply in each narrow part of subregion A which corresponded to an estuary (Figure 3(b)). High-concentration subregion B was located south of Fangcheng Port and west of Weizhou Island in an NNW-SSE orientation. Pollen concentrations there were commonly greater than 2000 grains/g, and the mean concentration of arboreal types reached the second highest level (mostly $>1000$ grains/g). High-concentration subregion $\mathrm{C}$ appeared as an $\mathrm{N}-\mathrm{S}$ orientated beaded chain south of Weizhou Island. Pollen concentrations there were generally greater than 2000 grains/g (>4500 grains/g in some places), and fern spores reach their second highest percentages (about 3000 grains/g). High-concentration subregion D, west of Qiongzhou Strait, was oriented NE-SW; pollen concentrations were generally over 2000 grains $/ g$. In some parts of subregion $\mathrm{D}$, fern spores made up as much as 3000 grains/g. Pollen concentrations were very low in lowconcentration subregions E $(<500$ grains $/ g)$, in the area south of Beihai; F (about 500 grains/g), lying in an NNE orientation to the northwest of Leizhou Peninsula; and G ( $<500$ grains/g), extending E-W in Qiongzhou Strait.

Arboreal types occurred at high concentrations in subregions $\mathrm{A}, \mathrm{B}, \mathrm{C}$ and $\mathrm{D}$, with the highest values in subregions A and B (Figure 2(b)). For instance, concentrations of Pinus could be as high as 1400 grains/g in subregion A and over 1000 grains/g in subregion B (Figure 2(e)), and those of Cyclobalanopsis/Castanopsis/Lithocarpus up to 180 and 120 grains/g, respectively (Figure 2(f)). Dacrydium pollen was mainly deposited in the western area and to the north of Hainan Island (Figure 2(g)). Mangrove pollen mainly appeared along the northeastern sea margins, southwest of Leizhou Peninsula, and northeast of Hainan Island (Figure 2(h)). The highest concentration of herbaceous types (>500 grains/g) was restricted to subregion A (Figure 2(c)), where Gramineae concentrations were over 120 grains/g (Figure 2(i)). Fern spores were most dense in subregions $\mathrm{A}, \mathrm{C}$ and D (Figure 2(d)). In particular, the concentration of Dicran-
opteris/Microlepria in subregion D reached 2000 grains/g (Figure 2(j)).

Distributions of pollen concentrations (Figure 4) indicated that (1) concentrations differed by an order of magnitude between high- and low-concentration subregions, reflecting distinct differences in deposition environments; and (2) the average concentrations of major pollen types in each high-concentration subregion were under the same order of magnitude, especially pollen components with diagnostic significance for vegetation belts such as Dicranopteris, Dacrydium, Cyclobalanopsis/Castanopsis/Lithocarpus, mangrove types, and 31 typical tropical-subtropical arboreal types (such as Euphorbiaceae, Altigia, Moraceae, Sapindaceae, Anacardiaceae, Myrtaceae, Elaeocarpus, Icacinaceae, Samydaceae, Guttiferae, Caesalpiniaceae, etc.). The convergence of pollen deposition patterns across such a vast range could be resulted from transportation, deposition, re-transportation and redeposition by seawater. Therefore, the vegetation of surrounding areas (Guangxi, Hainan Island, Leizhou Peninsula and northern Vietnam) could be documented by the pollen assemblages of surface sediments.

Based on pollen distributions in the study area, pollen assemblages could be classified into three types. The first type, represented by deposition subregion A, was characterized by abundant herbaceous pollen (mean percentage $31.0 \%$, mainly Gramineae, $18.8 \%$, and Cyperaceae, $1.6 \%$ ). Pollen assemblages in subregions $\mathrm{B}$ and $\mathrm{C}$ belonged to the second type, with high percentages of arboreal types (81.8\%), such as Pinus $(59.8 \%$ and $64.6 \%$, respectively). The third type, with the highest percentage of fern spores $(52.6 \%-$ $74.4 \%$ ), included the pollen assemblages of subregions D, E, $\mathrm{F}$ and $\mathrm{G}$ with a predominance of Dicranopteris/Microlepria (36.0\%-88.0\%) (Figure 5). For the third type, the representation of Cyclobalanopsis/Castanopsis/Lithocarpus (6.7\%$9.6 \%)$, mangrove types $(0.6 \%-1.3 \%)$, and tropical-subtropical arboreal types $(8.2 \%-11.0 \%)$ were higher than in the other deposition subregions. Subregion $G$ differed from subregions $\mathrm{D}, \mathrm{E}$ and $\mathrm{F}$ in its higher percentages of those pollen types. Concentrations of fern spores were higher in the 


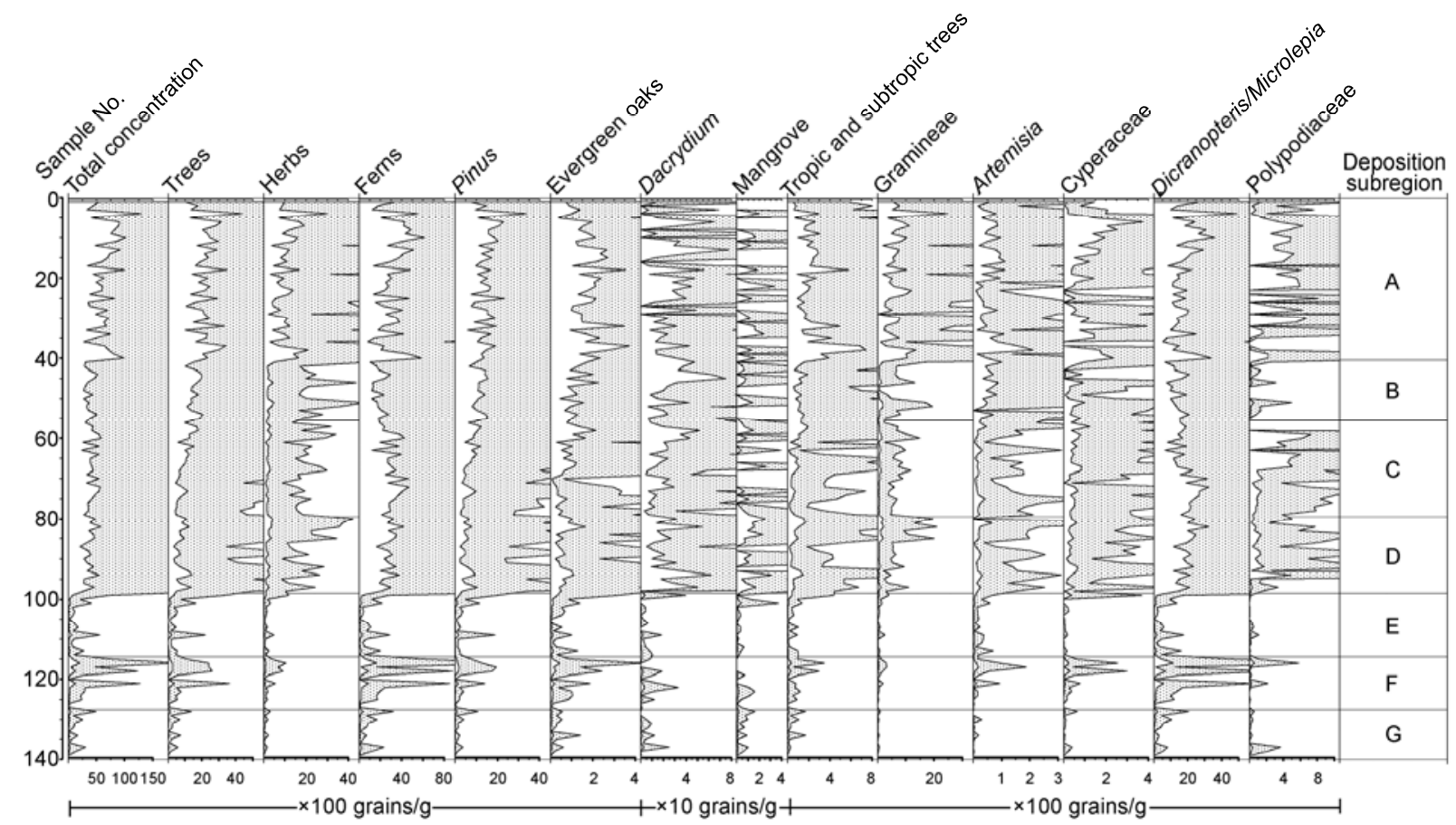

Figure 4 Concentration diagram of major pollen types in various deposition subregions (shaded area represents a 10-times magnification). Evergreen oaks represent Cyclobalanopsis/Castanopsis/Lithocarpus.

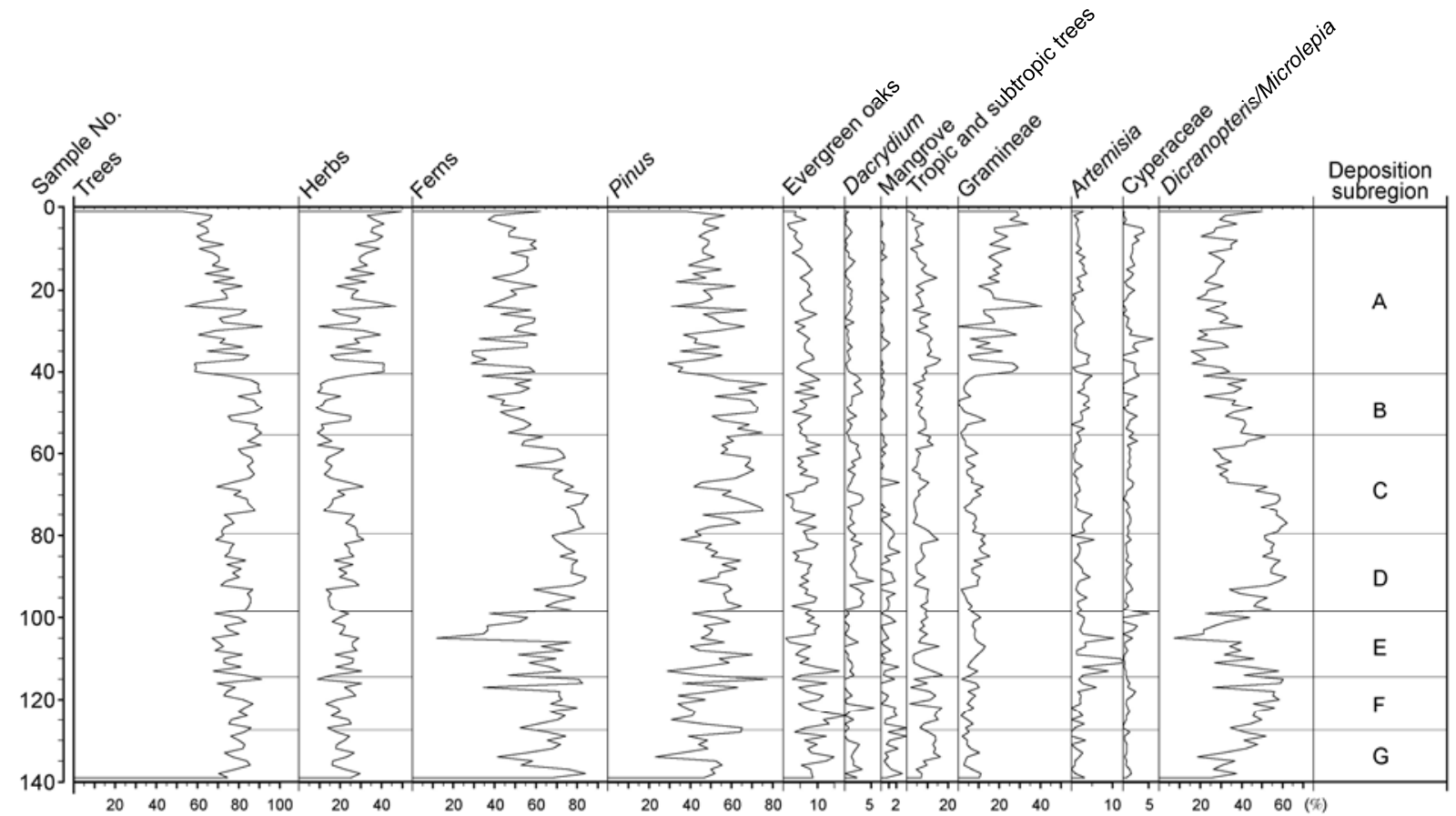

Figure 5 Percentages of major pollen types in various deposition subregions. Evergreen oaks represent Cyclobalanopsis/Castanopsis/Lithocarpus.

eastern Beibu Gulf (subregions D, E, F and G), while arboreal types dominated the central and the western areas (subregions B and C), and herbaceous types (Gramineae and Cyperaceae) were most dense in the northern areas. Therefore, there were marked differences among pollen assemblages in the eastern, central, western and northern areas of the study area.

\section{Discussion}

\subsection{Pollen assemblages and grain size distribution}

The four high-concentration subregions in the Beibu Gulf correlate well with known sedimentation regions of very fine silt and fine silt $[22,23]$ with average grain sizes greater than $7.0 \Phi(<0.008 \mathrm{~mm})$. Surface sediments in the three 
low-concentration subregions were fine sand with average grain sizes less than $3.5 \Phi$ (very fine sand $>0.088 \mathrm{~mm}$ ) and less than $2.5 \Phi$ (fine sand $>0.177 \mathrm{~mm}$ ), reflecting strong hydrodynamic forces during pollen deposition. Because the grain size of fine sand $(0.177-0.088 \mathrm{~mm})$ is similar to the diameter of large pollen grains, and because pollen grains are much lighter than minerals, pollen grains are unlikely to be deposited under the hydrodynamic conditions as fine sand. The high-concentration pollen subregions were close to the convergence centers of suspended matter indicated by calculations using the Gao-Collins Particle-size Trend Analysis Model (GSTA) [24]. High-concentration subregion $\mathrm{B}$ could be correlated with sediment convergence center A described by Ma et al. [25] through GSTA, and highconcentration subregions $\mathrm{C}$ and $\mathrm{D}$ correlated with sediment convergence centers $\mathrm{C}, \mathrm{D}, \mathrm{E}$ and F [22].

The correspondence between pollen deposition and grainsize distribution could be further validated by our grain-size analysis of surface sediments. Our results showed that the four high pollen-concentration subregions were restricted to regions with average grain sizes of $\Phi>5$ and the three low-concentration subregions to regions with average grain sizes of $\Phi<4$ (Figure 6(a)). The sand contents of sediments from high-concentration subregions were generally lower than $30 \%$, while that from low-concentration subregions were generally higher than 60\% (Figure 6(b)). In fact, pollen grains and suspended matter were deposited synchronously in the Beibu Gulf. There were abundant pollen grains deposited along with very fine and fine silts and only a small quantity along with very fine and fine sands.

\subsection{Pollen source areas and transmission mechanism}

Pollen assemblages in the surface sediments of the Beibu Gulf were mainly from terrestrial plants in the tropical-subtropical grasslands of southern Guangxi in the north and Leizhou Peninsula in the east; tropical rainforests and monsoon forests on Hainan Island in the south; tropical and monsoon forests and croplands in Vietnam in the west; and subtropical broad-leaved evergreen and subtropical coniferous forests in the drainage area of the Yuanjiang River.

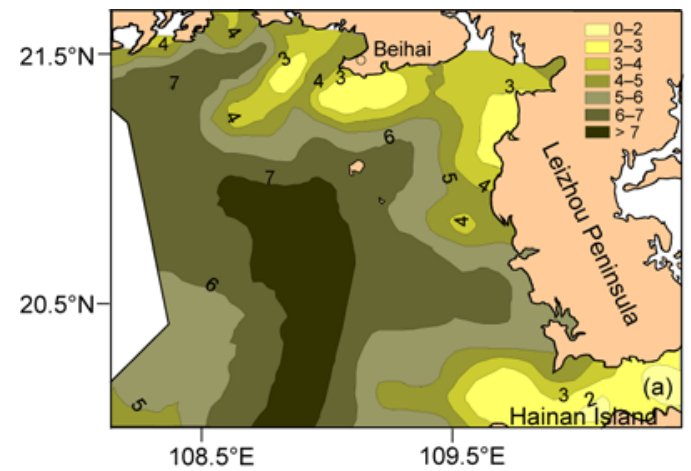

Pollen from the Pearl River drainage could be also transported into this area through Qiongzhou Strait. The main paths for pollen transmission in the study area were rivers, such as the Nanliu, Dafeng, Qinjiang, Maoling, Fangcheng, and Beilun rivers of Guangxi in the north, the Red River of Vietnam in the west, the Nandu River of Hainan Island in the south, and the Leizhou Qingnian Canal.

Atmospheric movement was also an important means by which pollen grains spread from continental margins into the study area. In winter, the prevailing northwest winds on the continent could transfer pollen from tropical and subtropical plants in the north into this sea area, including $\mathrm{Pi}$ nus pollen with air sacci and small pollen grains of evergreen Quercus/Castanopsis/Lithocarpus. In summer, the prevailing southwest winds can bring pollen grains of the tropical rainforests and monsoon forests of Vietnam and Hainan Island to this area. For example, Dacrydium pollen in the western sea area may have come mainly from Vietnam, and evergreen oak pollen in the eastern sea area may have been due to the vegetation of Hainan.

Pollen assemblages deposited in the eastern Beibu Gulf were mainly from terrestrial plants in the north, as indicated by high pollen concentrations in the northern Gulf and the decreasing trends in concentration towards the south. Pollen grains were carried into the sea by rivers of Guangxi in the north and gradually spread to the south sea basin. This transmission process induced the heterogeneity found in pollen distribution and, thus, the seven different pollen deposition subregions.

In high-concentration subregion $\mathrm{A}$, herbaceous pollen contents (mainly Gramineae, but including Cyperaceae) were higher than those of other deposition subregions. Pollen assemblages there could well reflect tropical and subtropical grasslands, where plants of Gramineae and Cyperaceae predominate in the drainage areas of rivers that flow into the Gulf.

The pollen assemblages in high-concentration subregions $\mathrm{B}$ and $\mathrm{C}$ contained more arboreal pollen (mainly Pinus) than other deposition subregions. These two high-concentration subregions probably received abundant pollen via the westward currents in Qiongzhou Strait, the eastward extension

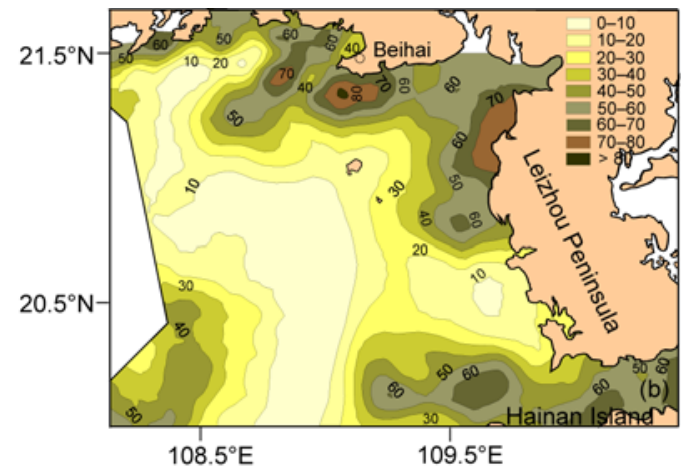

Figure 6 Distributions of average grain size (Ф) (a) and sand content (\%) (b) of surface sediments in the Beibu Gulf. 
of the cold water mass from the Red River, and northwest winds in the winter. High concentrations of arboreal pollen, such as Pinus and Cyclobalanopsis/Castanopsis/Lithocarpus, in Qiongzhou Strait could have come from the tropical and monsoon forests of Hainan Island carried by the southwest monsoon, summer cyclones, and the Nandu River and from pollen influx through coastal currents along western Guangdong [26,27]. The residual current in Qiongzhou Strait flows westwards throughout the year and thus takes arboreal pollen of the Strait region into the Beibu Gulf, resulting in high contents of arboreal types in deposition subregions $\mathrm{B}$ and $\mathrm{C}$.

Deposition subregions D, E, F and G were characterized by high contents of fern spores, mainly Dicranopteris/Microlepri $a$, which might have come from the Dicranopteris communities growing across vast areas of Leizhou Peninsula and Hainan Island after the destruction of natural vegetation [28]. Increasing surface erosion could lead to transmission of Dicranopteris pollen into the Beibu Gulf by surface runoff and rivers. In addition, pollen grains with sacci would be transported further by ocean currents [11-14], resulting in higher contents of fern spores in these deposition subregions.

In addition to the major pollen types with relatively high proportions mentioned above, there were pollens of Cyclobalanopsis/Castanopsis/Lithocarpus, some other tropical-subtropical arboreal types, and a small number of Tsuga and deciduous oaks in surface sediments of the Beibu Gulf. Source plants of these pollen types are very common in subtropical coniferous forests, broad-leaved forests in the surrounding areas [16], and in tropical rainforests and monsoon forests of northern Vietnam [15]. In the Beibu Gulf, cyclonic circulation currents occur at a gulf scale throughout a year (Figure 7) [17] and subordination cyclonic circulation currents in the northern area during the summer. Therefore, pollen grains from the Red River could have been spread to the eastern and northern Gulf by the northern cyclonic circulation currents. Meanwhile, pollen from Hainan Island could also have been carried to offshore areas of the Gulf by gulf-scale cyclonic circulation currents. In addition, northwest winds in the winter could have taken pollen into this sea area from tropical-subtropical plants in the north, while the southwest monsoon could have spread pollen of rainforests and monsoon forests of Hainan Island and Vietnam to this area. The combined effects of circulation currents and winds on pollen transmission could have given rise to high contents of Cyclobalanopsis/Castanopsis/Lithocarpus and tropical-subtropical arboreal pollen types in deposition subregions D, E, F, and G.

The high contents of Dacrydium pollen in high-concentration deposition subregions B, C, and D were distributed close to populations of Dacrydium growing mainly on Hainan Island [16] and in the tropical monsoon forests of $\mathrm{Vi}$ etnam [15]. Dacrydium pollen in the western sea area might have been due to the eastward movement of the cold water

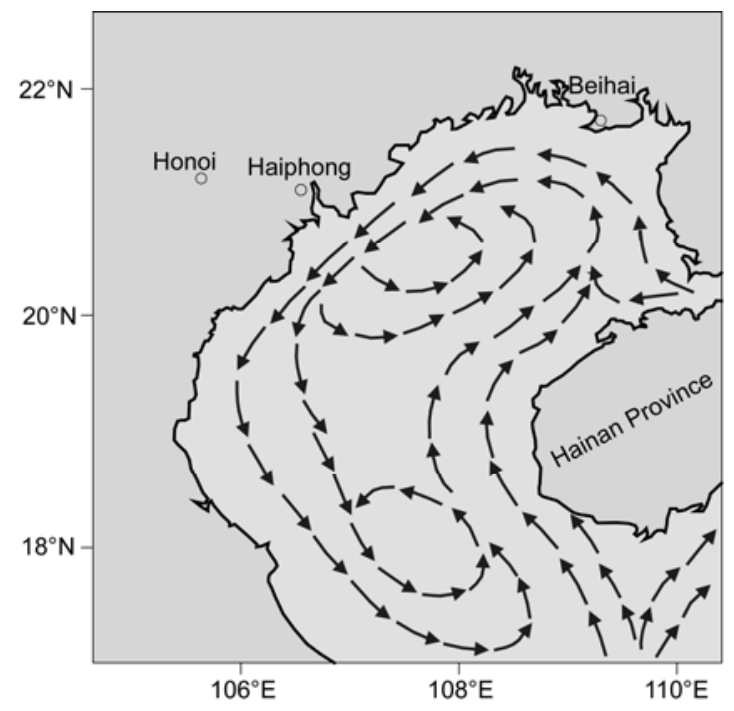

Figure 7 Current circulations in the Beibu Gulf during the summer [17].

mass from the Red River while, in the northern sea area of Hainan Island, it might have been brought by northward coastal currents along the Island. Meanwhile, the southwest monsoon was also very important for spreading pollen from Hainan Island and Vietnam to the Beibu Gulf. Mangrove pollen distributed mainly in deposition subregions D, E, F, and $\mathrm{G}$, which were located near the mangrove forests of Fangcheng Port, Qinzhou Gulf, Yingluo Port, Shankou $\left(21^{\circ} 28^{\prime} \mathrm{N}, 109^{\circ} 43^{\prime} \mathrm{E}\right)$ [29], Qishui of Leizhou Peninsula, Jiaowei [30], and Houshui Gulf of Hainan Island [31], indicating transmission by local runoff. Thus, high concentrations of Dacrydium and mangrove pollen were distributed adjacent to their source vegetation areas and consequently, could be used as indicator types.

\subsection{Sediment dynamic environment analysis}

Two processes are involved in pollen deposition in the eastern Beibu Gulf. One deposition process occurs in the inshore circalittoral zone, a main site for pollen deposition. There is frequent alternation of saline water and fresh water in this zone. The invasion of a salt wedge into the estuary region gives rise to a flocculated colloid effect of fine suspended matter and blocks the ebb tide. During this physico-chemical process, suspended matter, together with pollen grains, will deposit in the estuary or saline/fresh water frontal surface [32,33], such as deposition subregion A. In the inshore circalittoral zone, physical deposition processes would take place due to variations in topography, ocean current, tide, wave and seawater salinity, conditions that probably existed in deposition subregions D, E, F, and G.

Another deposition process occurs in nearshore zones with little fresh water, which probably dominates in deposition subregions $\mathrm{B}$ and $\mathrm{C}$. When ocean currents slow down or integrate with other currents, suspended matter in the 
upper layer will sink down to supply the middle or bottom layers. If concentrations of suspended matter in the bottom layer reach a certain threshold, this suspended matter will begin to deposit [22] synchronously with pollen grains. If the suspended matter in the upper layer remains at high concentrations or is supplied consistently, huge amounts of pollen deposition will take place, resulting in the pollen deposition subregions seen here. This physical process mainly occurs in nearshore zones. However, if the ocean currents speed up, a fraction of the pollen grains begin to move again, especially those types that tend to remain suspended.

In summary, seven deposition subregions in the eastern Beibu Gulf could be classified into six deposition environments based on dominant factors for pollen deposition. (1) Deposition subregion A was located near estuaries. The integration of fresh water and saline water from coastal currents and tides resulted in a frontal surface within the estuary region, leading to flocculation and deposition of suspended matter. Meanwhile pollen grains carried by rivers tended to deposit within the estuary region, although some of them entered the sea basin through ocean currents. As a result, pollen assemblages in the estuary appeared at high concentrations and were dominated by arboreal and herbaceous pollen types. (2) Deposition subregion D at the west end of Qiongzhou Strait was dominated by northwestward and westward tides. Ocean currents slow down after passing through the strait, depositing sediments and pollen grains and forming of pollen deposition subregions. (3) Deposition subregion $\mathrm{C}$ lies to the west of Leizhou Peninsula. The suspended matter in the western coastal area of Leizhou Peninsula dispersed and gradually deposited with increasing water depth and weakening hydrodynamic forces, resulting in abundant pollen deposition to the south of Weizhou Island. Pollen assemblages in this area were characterized by high concentrations and high contents of fern spores (Dicranopteris). (4) In deposition subregion B to the west of Weizhou Island, three ocean currents interact with one other, including highly saline water of Qiongzhou Strait from the east [20], the eastward extension of the Red River fresh water mass from the west [19], and cold water upwelling moving northwards from the northern South China Sea [18]. As a result of huge water flows combined with low hydrodynamic forces caused by current convergence, pollen grains tend to deposit, resulting in high pollen concentrations in surface sediments of this area. (5) Subregions E and F were located in the seas south of Beihai and northwest of Leizhou Peninsula, respectively, where sea water is relatively shallow, with a maximum depth of $6 \mathrm{~cm}$ during the summer southwest monsoon season [17]. Due to strong wind waves and repeated wash, sediments together with pollen grains tend to suspend, resulting in coarse sediments and low surface-pollen concentrations there. (6) Subregion $\mathrm{G}$ was situated in Qiongzhou Strait. As a result of strong tidal currents with a maximum velocity of more than $2 \mathrm{~m} / \mathrm{s}$ [27], the sea bed is subject to constant wash, and suspended matter can barely deposit. The strong hydrodynamic forces induce coarse sediments on the seabed and greatly disadvantage pollen deposition, resulting in low surface pollen concentrations there.

The estuary area is not only an important access for pollen grains entering the sea basin but also a major pollen deposition region. Coastal regions can also accumulate pollen grains because of the cyclic movements of tides. Although ocean currents on a gulf scale tend to spread pollen, the interactions of multi-currents could lead to pollen accumulation and deposition. Low surface pollen concentrations in the northeast shallow-water regions of the eastern Beibu Gulf could be attributed to repeated washing and sediment floatation caused by severe summer wave activities. Meanwhile, strong tides in Qiongzhou Strait could lead to washing of the seabed and little pollen deposition, resulting in low surface pollen concentrations in this region.

\section{Conclusions}

(1) The distribution of pollen concentrations of surface sediments is heterogeneous in the eastern Beibu Gulf. Five pollen regions can be distinguished in this sea area, including pollen region I, dominated by herbaceous pollen types; region II, with predominant arboreal pollen; region III, with abundant fern spores; region IV, characterized by large amounts of fern spores and arboreal pollen types (especially mangrove types); and region $\mathrm{V}$, rich in arboreal types (especially Cyclobalanopsis/Castanopsis/Lithocarpus) and fern spores. Four high-concentration subregions with abundant pollen deposition (3600-5800 grains/g) and three low-concentration subregions with poor pollen deposition (146-818 grains/g) could be recognized within these regions.

(2) The distribution pattern of surface pollen assemblages is consistent with that of surface sediment grain sizes. Sediments from high-concentration subregions were very fine and fine silts (mean grain size $>7.0 \Phi,<0.008 \mathrm{~mm}$ ), and those from low-concentration subregions were fine sand $(<3.5 \Phi,>0.088 \mathrm{~mm})$.

(3) Fern spores appear in high percentages on the east margins of the eastern Beibu Gulf basin, while arboreal types such as Pinus showed increasing trends towards the central basin. Herbaceous pollen reaches high percentages in nearshore areas near their source vegetation, and Dacrydium and mangrove pollen show low percentages and distribute in the vicinity of their source plants.

(4) Various sediment dynamic environments are indicated by deposition regions with different pollen concentrations and pollen assemblages. The estuary region is a major deposition site for pollen grains. Coastal regions can be pollen accumulation areas due to the cyclic movements of tides. Although ocean currents on a gulf scale tend to spread pollen grains, the interaction of multiple currents can lead to pollen accumulation and deposition. On the contrary, low 
surface pollen concentrations in the northeast shallow regions of the eastern Beibu Gulf can be attributed to repeated washing and floatation caused by severe summer wave activities. Strong tides in Qiongzhou Strait can lead to washing of the seabed and disadvantage pollen deposition, resulting in low surface pollen concentrations there.

Different sediment dynamic environments could give rise to variations in pollen concentrations and pollen assemblages among the regions of an individual sea area. Therefore, the influences on pollen assemblages from sediment dynamic conditions and sedimentary differentiation must be taken into consideration during the reconstruction of paleovegetation and paleoclimate and quantitative interpretation of paleoclimatic factors.

The authors would like to thank colleagues in the group of Project 908-01-CJ16 in the State Oceanic Administration for their assistance in sampling and data collection. We are grateful to Professor Xia Yonghua for his valuable suggestions, Professor Wang Shuming for his constructive comments on the manuscript, and Professor Zhang Yulan for her help in pollen identification. Thanks are also given to Li Yunling, Xu Ning, Zhu Qing and Chen Guoyan for their work on pollen counting. This work was supported by the Chinese Offshore Investigation and Assessment Project (908-01-ZH2) and the National Marine Public Welfare Research Project (200805063-3).

1 Muller J. Palynology of recent Orinoco delta and shelf sediments. Micropaleontol, 1959, 5: 1-32

2 Melia M B. The distribution and relationship between palynomorphs in aerosols and deep-sea sediments off the coast of Northwest Africa. Mar Geol, 1984, 58: 345-371

3 Hooghiemstra H, Agwu C O C. Distribution of palynomorphs in marine sediments: A record for seasonal wind patterns over NW Africa and adjacent Atlantic. Geol Rundsch, 1986, 75: 81-95

4 Hooghiemstra $\mathrm{H}$, Beug H J. Pollen and spore distribution in recent marine sediments: A record of NW-African seasonal wind patterns and vegetation belts. Meteor-Forsch-Ergebn C, 1986, 40: 87-135

5 Dupont L M, Agwu C O C. Environmental control of pollen grain distribution patterns in the Gulf of Guinea and offshore NW-Africa. Geol Rundsch, 1991, 80: 567-589

6 Campo E V, Bengo M D. Mangrove palynology in recent marine sediments off Cameroon. Mar Geol, 2004, 208: 315-330

7 Beaudouin C, Suc J-P, Escarguel G, et al. The significance of pollen signal in present-day marine terrigenous sediments: The example of the Gulf of Lions (western Mediterranean Sea). Geobios, 2007, 40: 159-172

8 Crouch E M, Mildenhall D C, Neil H L. Distribution of organicwalled marine and terrestrial palynomorphs in surface sediments, offshore eastern New Zealand. Mar Geol, 2010, 208: 315-330

9 Wang K F, Wang Y J, Xu J S, et al. Sporopollen and Algal Assemblages in the Yellow Sea Sediments (in Chinese). Beijing: China Ocean Press, 1987. 9-23

10 Wang K F, Sun Y H, Zhang Y L, et al. Sporopollen and Algal Assemblages in the East China Sea Sediments (in Chinese). Beijing: China Ocean Press, 1987. 10-27

11 Yang J W, Chen X L. Sporepollen in surface sediments of tidal flat in north coast of Hangzhou Bay (in Chinese). Mar Geol Quat Geol, 1985, 5: 101-108

12 Sun X J, Li X. Different dynamics and routes of modern pollen transport in the northern and southern parts of the South China Sea (in Chinese). Sci China Ser D-Earth Sci, 1998, 41: 494-498

13 Zhang Y L, Zhang W D, Wang K F, et al. Studies on the relationship between sporopollen of surface sediments and vegetation of the continental margin in the northeastern South China Sea (in Chinese). Mar Sci Bull, 2002, 21: 28-36

14 Zhang Y L, Long J P. Studies on the relationship between sporopollen of submarine surface sediments and vegetation around Hainan island. J Mar Sci, 2007, 25: 23-30

15 Sun X J, Li X, Beug H-J. Pollen distribution in hemipelagic surface sediments of the South China Sea and its relation to modern vegetation distribution. Mar Geol, 1999, 156: 211-226

16 Editorial Board of the Vegetation Atlas of China. Vegetation Atlas of China (in Chinese). Beijing: Science Press, 1980. 884-916

17 Xia H Y, Li S H, Shi M C. A 3-D numerical simulation of winddriven currents in the Beibu Gulf (in Chinese). Acta Oceanol Sin, 2001, 23: 11-23

18 Sun S W, Wang Y, Lan J. Hydrographic condition and circulation in the Beidu Gulf in winter and summer of 2006 (in Chinese). In: Hu J Y, Yang S Y, eds. Oceanic Study in Beibu Gulf. Beijing: China Ocean Press, 2008. 64-72

19 Cheng Z Z, Hu J Y, Sun Z Y, et al. Sectional features of temperature and salinity in Beibu Guly during July-August, 2006 (in Chinese). In: Hu J Y, Yang S Y, eds. Oceanic Study in Beibu Gulf. Beijing: China Ocean Press, 2008. 79-87

20 Yang S Y, Chen B, Li P L. A study of the characteristics of water transport from the South China Sea into Beibu Bay via the Qiongzhou Strait in summer in terms of temperature and salinity data (in Chinese). Trans Oceanol Limnol, 2006, 1: 2-7

21 Faegri K, Ivrsen J. Textbook of Pollen Analysis. 3rd ed. Oxford: Blackwell, 1989. 295

22 Chen L, Li T J, Xu D. Sediment grain size characteristics and distributions patterns in Beibu Gulf (in Chinese). Trop Geogr, 2010, 30: 587-590

$23 \mathrm{Zu} \mathrm{Z} \mathrm{W,} \mathrm{Ma} \mathrm{F,} \mathrm{Zhang} \mathrm{F,} \mathrm{et} \mathrm{al.} \mathrm{Sediment} \mathrm{transport} \mathrm{trend} \mathrm{analysis} \mathrm{in}$ the North-eastern part of Beibu Gulf (in Chinese). In: Hu J Y, Yang S Y, eds. Oceanic Study in Beibu Gulf. Beijing: China Ocean Press, 2008. 143-154

24 Gao S, Miehael C. The use of grain size trends in marine sediment dynamics (in Chinese). Sci Found Chin, 1998, 4: 241-246

$25 \mathrm{Ma} \mathrm{F}, \mathrm{Xu} \mathrm{Z} \mathrm{W}$, Zhang F, et al. Sediment grain size trend analysis and transport patterns in the eastern part of Beibu Gulf (in Chinese). In: Hu J Y, Yang S Y, eds. Oceanic Study in Beibu Gulf. Beijing: China Ocean Press, 2008. 143-154

26 Chen D S, Chen B, Yan J H, et al. The seasonal variation characteristics of residual currents in the Qiongzhou Strait (in Chinese). Transa Oceanol Limnol, 2006, 2: 13-17

27 Yang S Y, Bao X W, Chen C S, et al. Analysis on characteristics and mechanism of current system in west coast of Guangdong Province in the summer (in Chinese). Acta Oceanol Sin, 2003, 25: 1-8

28 Zheng Z, Cour P, Zhou H P, et al. Modern pollen in Hainan Islad, southern China: Altitudinal pollen distibution in the tropical rain forest (in Chinese). Acta Palaeontol Sin, 2002, 41: 487-496

29 Li Y Y. Current situation and ecological protection of mangrove wetland in Guangxi (in Chinese). Resour Surv Environ, 2008, 29: 55-60

30 Zou F S, Yang Q F, Cai J Q, et al. Avian diversity on mangrove wetland of Leizhou Peninsula (in Chinese). Chin J Ecol, 2008, 27: 383-390

31 Zhang G G, Liang W, Qian F W, et al. Influence of mangrove forests on waterbirds in Hainan Island (in Chinese). Sci Silva Sin, 2008, 44: 97-100

32 Xu J L, Li Y X, Cai F X, et al. Evolution of Shoal and Channel of Lingdingyang Ocean in the Pearl River Estuary (in Chinese). Beijing: China Ocean Press, 1985. 34-36

33 Dong Y H, Hui X X, Wang X L. A review on sediment movements in the ocean, coast and estuary (in Chinese). Water Resour Electr Power, 2009, 35: 1-24

Open Access This article is distributed under the terms of the Creative Commons Attribution License which permits any use, distribution, and reproduction in any medium, provided the original author(s) and source are credited. 